\title{
Francisco de Miranda en La Habana $(1780-1783)$
}

\section{Francisco de Miranda in Habana (1780-1783)}

\author{
Wilfredo Padrón Iglesias* \\ Yakelín Hernández Estrada**
}

Resumen: el presente artículo aborda la presencia de Francisco de Miranda en Cuba, entre 1780 y 1783, considerado uno de los periodos más complejos de su trayectoria. Se realizó una valoración de los factores fundamentales que incidieron en su formación intelectual y trayectoria militar durante la etapa abordada. Las fuentes utilizadas se corresponden con documentos de su archivo personal y otros resguardados en los archivos cubanos, así como textos de prestigiosos estudiosos de su obra y pensamiento. Como resultado se valoran las contradicciones que provocaron su enfrentamiento con los dos principales poderes hispanos de entonces: la Corona y la Inquisición. Estos hechos provocaron su salida del ejército español y conformaron el preámbulo para la formación de sus primeras ideas independentistas a favor de Hispanoamérica.

PaLABRAS Clave: Francisco de Miranda, La Habana, Inquisición, Caribe, España.

ABSTRACT: This article deals with the presence of Francisco de Miranda in Cuba, between 1780 and 1783, considered one of the most complex periods of his career. For the preparation of this work assessing the key factors that influenced his intellectual training and military career during the stage was developed. The sources used correspond to documents from his personal archives and others from the Cuban archives and texts of prestigious scholars of his work and thought. The contradictions that provoked his clashes with the two major powers of the time, Hispanic Crown and Inquisition are considered. These facts led to his departure from the Spanish army and formed the prelude to the formation of his first ideas of independence for Latin America.

Key wordS: Francisco de Miranda, La Habana, Inquisition, Caribbean, Spain.

Recibido: 12-02-2019

Aceptado: 23-10-2019

* Universidad Abierta para Adultos. Santiago de los Caballeros, República Dominicana (wilfredopadron@uapa.edu.do).

* Universidad Abierta para Adultos. Santiago de los Caballeros, República Dominicana (yakelinhernandez@uapa.edu.do). 
FRANCISCO DE MiRANDA EN LA HABANA (1780-1783)

Ni quien escribe ni quien lee la bistoria deberá limitar su atención a una simple exposición de los hechos: deberá tener en cuenta todo lo que los precedió, acompañó o siguió, porque si se le quita a la bistoria toda explicación de causa, principio o motivo y de la adaptación de los motivos al fin, lo que queda es un mero panorama nada instructivo y aunque pueda agradar de momento no tiene valor perdurable.

Polibio, historiador griego

más de doscientos años de distancia, los factores que impulsaron
a Francisco de Miranda y Rodríguez ${ }^{1}$ a salir precipitadamente de
Cuba y abandonar el ejército español, en una veraniega mañana
de junio de 1783, aún guardan vestigios de la incógnita que rodea a todo hecho de trascendencia histórica.

A su llegada a este territorio, en agosto de 1780, Miranda ya acumulaba más de una década en el ejército ibérico, sirviendo tanto en la península como en posesiones hispanas en África. En este periodo, si bien su desempeño personal y profesional se caracterizó por expresiones de inconformidad y rebeldía, no mostraba señales que permitieran presagiar que durante su posterior estancia en Cuba sus relaciones con el gobierno español se tensarían al límite, al punto de iniciar un proceso de irreversible distanciamiento.

${ }^{1}$ Sebastián Francisco de Miranda Rodríguez Ravelo y Espinosa nació el 28 de marzo de 1750, en Caracas, Venezuela. Con 21 años de edad se trasladó a España con el objetivo de ingresar al ejército. Entre 1780 y 1783 sirvió en el Caribe, como parte de las tropas españolas que participaron en la guerra de independencia de las colonias inglesas en Norteamérica. En este último año, una vez alejado del ejército español, emprendió un periplo que lo llevó a Estados Unidos, Rusia, Inglaterra y otros territorios asiáticos y europeos, al tiempo que planeó y lideró varios proyectos para alcanzar la independencia de Hispanoamérica. Fue apresado en Venezuela, en 1812, al término de la I República que se había instaurado en ese país dos años antes. Murió en una cárcel de Cádiz, España, el 14 de julio de 1816. 
Estas circunstancias históricas convierten al trienio cubano de Miranda en un punto de giro esencial para su vida y en el contexto donde se fraguaron las condiciones que permitieron el inicio de las más importantes etapas de su trayectoria política. ${ }^{2}$

A pesar de su importancia, historiadores como Bencomo (2000) Nucete-Sardi (1956), Spencer (1967) y Salcedo (1981), le otorgan nula o baja importancia a su estancia en Cuba y el Caribe, y resaltan su desempeño a partir de 1783, cuando comenzó un intenso recorrido que lo llevó a los nacientes Estados Unidos de América, parte de Asia y Europa. Respecto al trienio anterior, Salcedo y Nucete-Sardi, por ejemplo, sólo conceden relevancia a la presencia de Miranda entre las tropas españolas que se enfrentaron a Inglaterra por la posesión de La Florida, en $1781{ }^{3}$

Otros autores, como el destacado historiador Parra-Pérez (1988), también hace énfasis en el impacto que tuvo en el ideario mirandino su paso por Estados Unidos, entre 1783 y 1784, sin ponderar con suficiencia los acontecimientos anteriores a su llegada a este territorio.

De otra parte, historiadores como Córdova (1954), Laútico (1961), Pérez-Cabrera (1950), Bohórquez (2003) y Guerra Vilaboy (2006), le otorgan significativa importancia a la estancia de Miranda en Cuba. A este respecto, señalan varios factores que incidieron en su trayectoria, como su participación en misiones militares, el enfrentamiento con autoridades

${ }^{2}$ A juicio de este autor, la trayectoria política de Miranda puede estructurarse en cuatro etapas fundamentales. La primera comienza con su llegada a España en 1771, con el objetivo de ingresar a las armas reales, y cierra con su precipitada salida de Cuba en 1783, tras haber comenzado a separarse del gobierno ibérico; la segunda etapa inicia con su recorrido por Estados Unidos en este último año y se extiende hasta 1790, momento en el que Miranda da por concluidos sus viajes a través del mundo y encamina todos sus esfuerzos para lograr la independencia de Hispanoamérica. La tercera se corresponde con el inicio de estos proyectos y gestiones emancipadoras en Europa y Estados Unidos hasta su llegada a Venezuela en 1810, con el propósito de participar en los acontecimientos que sacudían a esta colonia hispana; la cuarta y última etapa comprende su desempeño en las luchas independentistas de la región, en el contexto de la Primera República de Venezuela, entre 1810 y 1812.

${ }^{3}$ A modo de ejemplo puede verse el discurso de Salcedo en ocasión del bicentenario de la participación de Miranda en Pensacola, publicado en 1981, en Venezuela, por el Boletín de la Academia Nacional de la Historia. 
isleñas y metropolitanas, su responsabilidad como edecán del capitán general de la isla, el vínculo con la alta jerarquía militar, económica y política de Cuba y otros territorios caribeños, y el proceso que le siguió la Inquisición.

Estos autores, aunque realizan valiosas aportaciones, no analizan con suficiencia la temática en cuestión, debido a múltiples causas, entre las que destacan el no ser parte de los objetivos de sus investigaciones, no haber dispuesto de la suficiente información o debido a carencias metodológicas en sus análisis.

Ante esta situación y con el propósito de aportar a la comprensión de la trayectoria política de una de las figuras más importantes del proceso independentista hispanoamericano, el presente estudio se propone valorar los factores que incidieron en el pensamiento de Francisco de Miranda durante su estancia en Cuba, que lo condujeron a iniciar un proceso de ruptura con el ejército y el gobierno español.

Para satisfacer este propósito, se analizan los antecedentes relacionados con su desempeño en África y Europa, entre 1771 y 1780. Del siguiente trienio, se abordan las actividades que realizó como oficial del ejército español, en Cuba, otros territorios del Caribe y Norteamérica. Asimismo, la continuidad de su preparación intelectual, la consolidación de sus relaciones sociales, así como sus discrepancias con personalidades que representaban los más altos poderes militares, civiles y eclesiásticos del Caribe insular y la metrópoli hispana.

La valoración del conjunto de estos factores devela las contradicciones que incidieron en el pensamiento de Miranda y que lo condujeron a iniciar un proceso de ruptura con el gobierno español. En un sentido más profundo, permiten comprender el proceso de maduración de su ideario político, que apenas seis meses después de su salida de Cuba alcanzaría un peldaño superior al expresar sus primeras ideas sobre la independencia de Hispanoamérica. 
Antes de la llegada de Francisco de Miranda a Cuba, durante su estancia en la península ibérica y en el norte de África, entre 1771 y 1780, varios factores favorecieron la ampliación de su pensamiento político, militar y cultural.

En primer orden, se encuentra su conocimiento de diversos sitios de Europa y África. Luego de su incorporación al Regimiento de la Princesa con los grados de capitán, Miranda participó en la defensa del enclave militar y comercial español en Melilla, al norte de África, y prestó servicios de guarnición en las ciudades españolas de Málaga, Cádiz y Madrid. También en este periodo, pero en virtud de una invitación personal, entre fines de 1775 y los primeros meses del siguiente año, visitó el Peñón de Gibraltar, en manos inglesas desde 1713. Esta breve estancia constituyó su primer contacto directo con la cultura británica y presumiblemente fue el escenario donde conoció al acaudalado comerciante inglés John Turnbull, quien llegó a ser uno de sus colaboradores más cercanos y principal sostén financiero.

Un segundo factor a tener presente es su acelerado crecimiento cultural, unido a la aparición de las graves adversidades que ello le acarreó, sobre todo las venidas del Santo Oficio.

Su dominio de lenguas extranjeras, así como del latín, posibilitó acercarse a las obras de importantes intelectuales clásicos y contemporáneos, a pesar de que con ello transgredía las fuertes prohibiciones del régimen eclesiástico y estatal español. Fruto de esta vocación nació su propia colección bibliográfica, que a su salida para el Caribe en 1780 ya alcanzaba los 625 libros. En ella se encontraban casi todas las obras representativas del pensamiento más avanzado de la Europa decimonónica, e incluía temas de filosofía, política, estrategia militar, economía, artes, historia y literatura general.

Entre las obras más controvertidas, por representar un cuestionamiento al pensamiento tradicional y sus valores fundamentales, ${ }^{4}$ estaban:

${ }^{4}$ Por ejemplo, entre los libros coleccionados por Miranda se encontraban El espiritu de las leyes, de Montesquieu, prohibido por la Inquisición en 1762; las obras completas 
Brevísima relación de la destrucción de las Indias, del Padre Las Casas; Cartas sobre los libre pensadores, del gobierno y de la naturaleza bumana, de John Locke; Investigaciones filosóficas sobre los americanos, de De Pauw; e Historia filosófica y política del establecimiento y del comercio de los europeos en las dos Indias, del Abate francés Guillaume Thomas François Raynal. También sobresalían los libros de David Hume, William Burke y otros autores (Uslar 1966).

Estos y otros textos fueron intercambiados con otros oficiales que compartían sus mismas inquietudes y con quienes tuvo la oportunidad de intercambiar sus criterios. Entre éstos se encontró el peruano Manuel Villalta y un oficial francés de apellido Mertens.

Con Villalta sostuvo conversaciones de fuertes críticas a la fe y las prácticas católicas de los ámbitos hispanos. De estos intercambios se conoció en el juicio seguido por la Inquisición contra el peruano, cuando uno de los testigos, de nombre Luis Carrera y también capitán del Regimiento de la Princesa, aseguró que "en Cádiz, en su mismo cuarto y ante Francisco de Miranda, hablando con Don Pedro Rodríguez, Capitán de Saboya, diciendo éste de un sujeto de Madrid que era tan sabio y que de religión ninguna, respondió el reo (Villalta) que ya ningún hombre sabio tenía religión" (García 1961: 431).

En consecuencia con este trasgresor proceder, desde la segunda mitad de la década de 1770, el Tribunal de la Inquisición en Sevilla le abrió una causa a Francisco de Miranda por los "delitos de proposiciones, retención de libros prohibidos y pinturas obscenas" (García 1961: 443).

Otro aspecto importante fueron las desavenencias que enfrentaron a Francisco de Miranda con algunos de los representantes del ejército hispano. Las más trascendentes fueron la sostenida con quien fuera temporalmente su jefe, el coronel Juan Roca, y la entablada con el inspector general del ejército, Alejandro O'Reilly. Además, en esta etapa Miranda sobresalió por su empeño de alcanzar condecoraciones, ascensos y traslados a posiciones militares de mayor relevancia. Una postura que a pesar de ser

de Voltaire, también condenado desde 1762, y las obras completas de Rousseau, prohibidas en 1764 (Kamen 1967: 279). 
presentada como una vía para incrementar su contribución al ejército y al rey, no estaba exenta de un elevado interés personal. ${ }^{5}$

Un aspecto interesante de la presencia de Miranda en la expedición que envió España en 1780 para enfrentar a Inglaterra en el Caribe y Norteamérica es el paradójico hecho de formar parte de una fuerza militar destinada a apoyar unas colonias para independizarse de su metrópoli.

Si nos atenemos a sus escritos personales, en ese momento Miranda no advirtió esta paradoja. Sus referencias a este hecho son muy posteriores e indirectas. Una muy breve se encuentra en la Representación que dirigió al rey en 1785, mientras la segunda se realizó en 1810 y por conducto de José María Antepara, con quien el venezolano colaboró en la elaboración de la obra South American Emancipation.

En resumen, si alrededor del joven oficial venezolano se fue conformando un desfavorable ambiente que lo acompañó hasta Cuba y el Caribe, los documentos que se conservan en su archivo, como sus cartas, diarios, esquelas, etcétera, señalan que en el campo político aún estaba identificado con su condición de americano español. O sea, algunas de sus conductas personales eran discordantes con el régimen hispano y pudieron haber presagiado la aparición de serias dificultades en su carrera profesional, pero no permitían asegurar que en el futuro inmediato se romperían los fuertes lazos que lo vinculaban a su metrópoli.

\section{DE OFICIAL ESPAÑOL AL COMIENZO \\ DE SU RUPTURA CON ESPAÑA}

Durante la travesía atlántica del Ejército de Operaciones de América, fuerza que integró Francisco de Miranda como capitán del Regimiento de Aragón, el jefe de la expedición designó al coronel Juan Manuel de Cagigal para la preparación de hospitales de campaña, con el objetivo de resguar-

${ }^{5}$ Entre los años 1774 y 1776 Miranda remitió varias cartas a altos jefes hispanos y al propio rey, con la solicitud de que fuera condecorado, ascendido o trasladado a otros cuerpos militares (Miranda 1978a: 327, 415, 423 y 463). 
dar a los enfermos de la expedición; como su edecán nombró a Francisco de Miranda, ambos criollos, ${ }^{6}$ que desde su estancia en España compartían una sincera amistad, acondicionaron campamentos sanitarios en las islas de Guadalupe, Dominica, Martinica, Santo Domingo y Puerto Rico.

En los días iniciales de agosto de 1780, la escuadra militar arribó al puerto de La Habana. Desde esta urbe y durante el siguiente trienio, Francisco de Miranda se desplazó por la región caribeña en cumplimiento de las misiones militares que le fueron encargadas (Padrón 2010).

Su desempeño estuvo influido por dos importantes circunstancias: su responsabilidad como edecán de Juan Manuel de Cagigal y el haberse convertido La Habana en el vórtice de la ofensiva hispana contra los ingleses, extendida por el Caribe insular, La Florida y Luisiana (Archivo Nacional de Cuba - en lo adelante ANC, Asuntos políticos, leg. 106, f. 2).

A pocos días de su llegada a Cuba, Miranda formó parte de las tropas hispanas que sitiaron y tomaron la plaza británica de Pensacola, Florida Occidental, entre abril y mayo de 1781 (Torres y Guerra 2018).

El diario que elaboró durante este periodo, en el que describe pormenorizadamente las operaciones que posibilitaron al ejército español ocupar la plaza, permite desmitificar dos aspectos esenciales de su trayectoria. En primer lugar, su presencia y desempeño en esta acción bélica obedece a su función como ayudante de Cagigal, lo que desmiente que haya comandado tropas de voluntarios venidas desde Cuba o que participó en estas luchas a título individual. Además, a diferencia de lo que también se ha sido afirmado en varios textos, su interpretación inmediata de esta victoria no se convirtió en una ponderación personal de la independencia que debían alcanzar las colonias hispanas. Como afirma Bohórquez "hasta ese momento, Miranda continuaba pensando como vasallo del rey

${ }^{6}$ Juan Manuel de Cagigal y Monserrat nació en Santiago de Cuba en 1738. Desde temprana edad se dedicó a la carrera de las armas, sirviendo en el Regimiento de Fijos de La Habana y en Nueva España, como ayudante personal de su padre. Al marchar éste a la península, Juan Manuel lo acompañó. Fue ascendido a capitán, teniente coronel y coronel. Participó en la ofensiva hispana contra Portugal y Africa, y en la incursión española que restableció la dominación ibérica sobre Río la Plata en 1776. 
de España; aun cuando se trataba de un vasallo un tanto iconoclasta" (Bohórquez 2003: 69).

Un hecho importante en su trayectoria es que la ocupación de tan importante puerto fue recompensada por el rey, lo que le permitió obtener su anhelado ascenso al grado de teniente coronel.

Un mes después de esta operación bélica, el navío que transportaba desde Pensacola hacia Nueva York al vencido general inglés John Campbell hizo escala en La Habana. Cagigal, que había sido nombrado interinamente capitán general y gobernador de Cuba, en virtud de sus obligaciones con los altos jefes enemigos, dispuso que éstos efectuaran un paseo por la ciudad en compañía del oficial español José Montesinos. Sin embargo, el recorrido se extendió hasta la Loma de Aróstegui, donde los visitantes pudieron ver las obras de carpintería y algunas piezas que se trabajaban en las afueras del Castillo de El Príncipe, importante fortificación para la defensa de la ciudad.

El análisis de la documentación relativa a este hecho, señala que Cagigal asumió que el incidente se debió más a la casualidad que a la premeditación oportunista del alto rival británico. En consecuencia, reprendió severamente a Montesinos por haber permitido que Campbell se acercara a las obras de la fortificación y exigió una fuerte amonestación, aunque sin trascendencia pública, para los oficiales encargados de la vigilancia de la fortaleza, por no haber impedido que soldados enemigos penetraran en la misma. Para concluir el asunto, subrayó las medidas a tener presentes para garantizar la seguridad del recinto (Miranda 1978b: 118).

Varios documentos y testimonios prueban que Francisco de Miranda estuvo ajeno a esta situación. El día de la visita de Campbell al Príncipe se encontraba en las afueras de la ciudad, visitando uno de sus amigos criollos, el Conde Casa Montalvo, en la finca Ojo de Agua, situada a tres o cuatro leguas de La Habana. Sin embargo, en poco tiempo sería señalado como el máximo responsable del incidente, convirtiéndose en blanco de una disposición Real que cruzó el Atlántico y que exigía su inmediato encarcelamiento. 
Por estos días, Miranda fue designado por Cagigal para desarrollar un canje de prisioneros con las autoridades de Jamaica, importante base bélica y comercial inglesa en la región caribeña. Su misión oficial encubriría la búsqueda de información militar y la adquisición de medios navales que facilitaran la intervención de las fuerzas españolas contra esa colonia británica.

Con estos propósitos, Francisco de Miranda zarpó del puerto de Batabanó el 14 de agosto de 1781 para arribar unos días más tarde a Jamaica. Mientras los términos del intercambio se concertaban, viabilizó con Cagigal el traslado a Cuba de varios grupos de personas enfermas y atendió algunas solicitudes de estudiantes (clérigos de menores) y familias criollas. Al mismo tiempo, concilió con el gobernador de Santiago de Cuba, Nicolás de Arredondo, el intercambio de prisioneros entre las partes (ANC, Asuntos Políticos, leg. 304, fs. 1, 2, 6 y 8). El capitán general de Cuba siguió el curso de las negociaciones de su edecán, mediante el intercambio epistolar con Arredondo (ANC, Correspondencia de los capitanes generales, leg. 30-A, fs. 49, 57, 52 y 59).

La complejidad militar y política de la misión secreta de Miranda en Jamaica lo obligaron a encubrir sus encargos con una actividad comercial, para lo que estableció un acuerdo con el comerciante inglés, Philip Allwood, de permitirle ingresar en La Habana, libre de impuestos, una determinada cantidad de mercancías. En cambio, el agente británico asumió la compra de los bergantines Porcupine y Three Friends, de la goleta Eagle y de otros útiles y efectos navales. No sospechó Miranda que este trato agregaría mayores complicaciones a su desempeño en el Caribe, convirtiéndose en otro punto sobre el que se apoyaría la corona hispana para emitir una nueva orden en su contra.

\section{ENTRE PUGNAS Y ACUSACIONES}

Después de tres meses de estancia en Jamaica Francisco de Miranda concluyó con éxito el Cartel de Canje, firmado el 13 de noviembre de 1781, 
mediante el que se restituyó al ejército español a 850 individuos de tropa y marinería. En su actividad secreta también fue muy efectivo: adquirió las mencionadas embarcaciones y dejó una proposición para la compra de cuatro fragatas corsarias provistas de 20 a 30 cañones; además acarreó lonas, jarcias y otros efectos navales. De igual modo, trasladó hacia Cuba importantes informaciones de índole militar sobre las fuerzas militares británicas asentadas en la isla, así como cartas marítimas y planos, con indicación de caminos, localidades, puertos, fondeaderos, playas, obras de fortificación, artillería, entre otros detalles de interés para la proyectada invasión española contra Jamaica (Miranda 1978b: 227).

De regreso a Cuba, el 13 de diciembre del año en curso y nuevamente por el Surgidero de Batabanó, Miranda estaba precisado a pagarle a Allwood su contribución para: "reponer los costos y atrasos que se le hayan ocasionado en auxiliar mis asuntos" (Miranda 1978b: 185). Así se lo comunicó a Cagigal, precisándole que había autorizado al comerciante inglés la libre entrada a La Habana de un monto de mercaderías por valor de seis a ocho mil pesos.

La propuesta mirandina fue aprobada de inmediato por Cagigal, mediante un oficio fechado el propio día 13 (Miranda 1978b: 193). Sin embargo, en el camino hacia La Habana la comitiva fue interceptada por los hombres del Resguardo de Rentas, en cumplimiento de las instrucciones del intendente habanero, Juan Ignacio de Urriza.

Este hecho provocó una fuerte pugna de poderes entre Cagigal y Urriza, en la que terminó por imponerse el gobernador y capitán general de la isla. Mas, el intendente, insatisfecho con la decisión adoptada y la forma en que su autoridad había sido obviada, envió a la corte ibérica una fuerte acusación en la que culpó a Miranda de aprovecharse de su condición de parlamentario y del dinero entregado para su misión para desarrollar actividades de contrabando; a Cagigal lo señaló como su protector.

Mientras estos pliegos cruzaban el Atlántico y llegaban a la corte ibérica, a principios de marzo de 1782 el gobernador de Cuba recibió dos comunicaciones del ministro de Indias, fechadas el 2 y 16 de noviembre de 1781, en las que se le ordenó apresar a Miranda y trasladarlo de manera 
inmediata a España. En la segunda orden el ministro Gálvez le comunicó que el Rey no aprobaba la designación del teniente coronel Francisco de Miranda para efectuar el canje de los prisioneros españoles detenidos en Jamaica, dado que:

ha sabido con sumo desagrado que al general Campbell y a otros oficiales suyos se les permitió ver las fortificaciones de esa Plaza, a influjo y en compañía de don Francisco de Miranda, Capitán del Regimiento de Aragón, que es un entusiasta apasionado de los ingleses. Con esta noticia, que los mismos enemigos han publicado en sus colonias, se ha servido S. M. mandar que inmediatamente separe V. E. a este oficial de su lado y que en primer aviso, o correo u otra embarcación que salga de ese puerto para cualquiera de estos Reinos de España, le envíe irremisiblemente a ellos, sin confiarle pliegos ni encargo alguno de su Real servicio (Miranda 1978b: 230).

Ante tan injusta acusación, Cagigal remitió al ministro José de Gálvez dos Cartas Reservadas y una Representación, fechadas el 5 de marzo de 1782, en las que expuso lo sucedido durante la estancia de Campbell en La Habana y le remitió todos los documentos relativos al caso. A favor de Miranda, argumentó que desde diciembre pasado ya había regresado, con indudable éxito, de su misión en Jamaica.

Es significativo que en estas primeras órdenes cursadas contra Miranda se trató de justificar su "condescendencia" con Campbell a partir de su "apasionamiento" por los ingleses. O sea, no sólo se usó un motivo falso para inculparlo, sino que se trató de agravar la violación introduciendo otra recriminación mucho más trascendente: premeditada inclinación hacia el enemigo. En las órdenes que se sucederán por el desacuerdo del Rey con los términos del canje establecido en Jamaica, su "inclinación" por los ingleses fue utilizada nuevamente para reiterar que el venezolano atentaba contra los intereses hispanos.

$\mathrm{Al}$ respecto, es necesario señalar que Francisco de Miranda no ocultaba su conocimiento y admiración hacia notables autores ingleses, dentro de los que se destacaba John Locke, del que poseía los tres tomos de sus Ensayos, el Essay Concerning Human Understanding y los dos Treatises 
of Government. Además, ya había atesorado en su biblioteca la History of Englad de David Hume y otra obra del mismo nombre, de Tobías Smollet. Sin embargo, estas lecturas pueden considerarse una actitud consustancial a su condición de hombre ilustrado y no un indicativo de que se subordinara ante los intereses políticos británicos, traicionando los valores hispanos que defendía.

También es interesante que a pesar de que la supuesta falta cometida por Miranda debía ser del conocimiento público, su apresamiento se ordenara con la más absoluta reserva. A ello se suma que ante un error de baja trascendencia se ordenaran medidas tan drásticas, incluyendo su traslado a España, cuando en el propio territorio cubano podía ser juzgado.

Sin conocer que nuevas órdenes reales se estaban remitiendo desde Madrid contra Francisco de Miranda y su protector Juan Manuel de Cagigal, en La Habana se prepararon nuevamente los navíos de guerra. Esta vez, como concebía el plan estratégico de los españoles en el Caribe, debía desalojarse a los ingleses asentados en Las Bahamas, ya que este archipiélago funcionaba como un centro de aprovisionamiento y refugio de naves enemigas.

Bernardo de Gálvez, comandante del ejército hispano en el Caribe, designó a Cagigal para emprender esta nueva acción militar, que se fijó para mediados de 1782. Miranda intervendría desde su puesto de edecán del gobernador habanero.

La nueva expedición conquistadora se hizo a la vela el 22 de abril de 1782, con 2000 hombres, entre los que se encontraban fuerzas reglamentarias, milicias de Pardos y Morenos y tropas voluntarias de Cuba, a bordo de 48 embarcaciones mercantes, una fragata norteamericana y 10 bergantines españoles (Placer 2015: 76).

El arribo de tan imponente flota a las costas de la isla de Nueva Providencia, capital del archipiélago bahamés, obligó a la inmediata rendición de las tropas británicas. Con esta victoria, además de la estratégica posición, se capturaron 274 soldados regulares, 328 milicianos, 199 cañones y 868 fusiles; así como 12 buques corsarios y 65 mercantes ingleses. La capitulación oficial fue firmada el 8 de mayo de 1782, por Francisco de 
Miranda, en representación de las fuerzas ibéricas, y John Maxwell, capitán general y comandante en jefe de las tropas británicas que dominaban las islas Bahamas (Albi 1987: 165).

Pero a su regreso a la capital cubana, Miranda y Cagigal se encontraron con desalentadoras noticias. No obstante las misivas enviadas al ministro de Indias en las que se argumentó la inocencia del criollo venezolano, se había emitido otra orden en su contra, esta vez fechada en Madrid el 11 de marzo de 1782, indicando que si aún no se le había enviado a España, se le retuviera inmediatamente en una fortaleza habanera (Miranda 1978b: 274).

Para Juan Manuel de Cagigal, las medidas no serían menores: en la propia fecha se había decidido su separación de la gobernación y Capitanía General de la isla y apenas siete días después se había indicado realizarle un juicio de residencia.

Esta nueva disposición contra Miranda estuvo impulsada por dos motivos. En primer orden se encontraba el desacuerdo del monarca ibérico con los términos acordados en el Cartel de Canje, al considerar que el artículo número 7 era contrario a las Reales Cédulas y Órdenes establecidas sobre el corso. Una causa que aunque no ha sido debidamente reconocida en otros estudios, dentro del conjunto por las que se intentó juzgar al venezolano es la que más se acerca a una violación de las líneas establecidas por España.

Como segunda causa se agregó el supuesto contrabando conducido desde la vecina isla inglesa, aprovechándose del dinero entregado por la Intendencia: "con el aparente objeto de socorrer los prisioneros (lo que no ejecutó), y con el verdadero designio de emplearlo (como lo practicó) en muchos géneros comerciales para transportarlos a esa isla (Cuba) en diferentes flagatruses, introducirlos clandestinamente y expenderlos en ella, a pesar de las severas prohibiciones que hay para hacer semejante negociación" (Miranda 1978b: 276).

En la propia misiva, José de Gálvez le comunicó a Cagigal que el Rey había desaprobado su conducta en todo el proceso litigado con Urriza, advirtiéndole que en el futuro no se mezclara en los asuntos de la Real Hacienda (Miranda 1978b: 277). 
Esta última disposición contra Miranda introdujo un cambio respecto a las precedentes. Mientras la orden del 2 de noviembre de 1781 indicó su detención y traslado a cualquiera de los "Reinos de España", la del 11 de marzo de 1782 exigió que se le recluyera en una fortaleza habanera. Una variación que no fue producto de la casualidad o el acomodo del proceso, sino que debió ser la resultante de la acción conjunta del Santo Oficio y el gobierno español.

Al respecto, las historiadoras Carmen M. Bohórquez Morán (2003) y Josefina Rodríguez de Alonso (1978) afirman que esta conexión pudo establecerse a través del padre Eleta, quien además de ser el confesor de Carlos III, ejercía un alto cargo en el Tribunal del Santo Oficio y por tanto debió tener conocimiento del proceso incoado contra Miranda. Además, si los procesos eran secretos para el público, no lo eran para los altos funcionarios inquisitoriales o del gobierno. Por ello, es también muy probable que Miranda tuviese razón al sospechar que el extraño proceder del inspector general Alejandro O'Reilly, durante su estancia en Madrid, guardase alguna relación con la Inquisición. El propio general le inquiriría: "por medios bien extraños e indecorosos" si oía misa, si tocaba la flauta y si leía libros filosóficos (Miranda 1978b: 423).

Además, según muestran los documentos inquisitoriales, mientras Francisco de Miranda permaneció en Europa su caso estuvo bajo la jurisdicción del Tribunal de Sevilla. Pero cuando en febrero de 1782 el Supremo Consejo tomó la decisión de que "se le apresara con embargo de bienes, se le siguiera su causa hasta la definitiva y al tiempo de su prisión se reconocieran las pinturas, libros y papeles que tuviese, recogiéndole los prohibidos" (García 1961: 443), hacía más de un año que el oficial venezolano residía en Cuba y por tanto se encontraba fuera del alcance de esta corte europea. Para llevar a vías de hecho la decisión, desde Sevilla se reenvió su caso al Consejo y éste lo remitió al Tribunal de Cartagena de Indias, que tenía jurisdicción sobre los Arzobispados de Santa Fe y Santo Domingo, y los Obispados de Cuba, Cartagena, Santa Marta, Panamá, Popayán, Puerto Rico y Venezuela. 
En consecuencia, mientras el proceso del Santo Oficio avanzaba, era preciso retener a Miranda en Cuba, muy probablemente hasta que la documentación llegara de Europa y el reo pudiera remitirse al tribunal de Cartagena. Además, en el Caribe se facilitaría la recogida de testimonios y la confiscación de materiales prohibidos para utilizarlos como pruebas en el proceso.

\section{LA DISCORDIA EN EL PARAÍSO}

Un factor que influyó negativamente en el desempeño de Francisco de Miranda fue los numerosos adversarios que enfrentó en tierras cubanas y caribeñas, varios de ellos investidos de altas responsabilidades políticas y militares.

Entre sus más notables desacuerdos se encuentran los sostenidos con el obispo Santiago José de Hechavarría, ${ }^{7}$ quien también tendría fuertes divergencias con Cagigal que llegarían incluso hasta la corte hispana.

Tras uno de estos incidentes, Hechavarría comunicó al ministro de Indias, José de Gálvez, que los conflictos con Cagigal estaban impulsados por la mala influencia de su edecán venezolano. De igual modo, José Saavedra, representante en el Caribe del ministro Gálvez, escribió en sus Memorias:

Por la tarde fui a ver al Obispo, que había tenido fuertes desazones con el gobernador Cagigal, hombre bueno en el fondo, pero de cuyo carácter fácil e incauto habían abusado cuantos le rodeaban, especialmente un tal Montesinos, cabeza muy desbaratada, y Miranda, talento claro, pero espíritu inquieto y peligroso que tanto ha dado después que decir y que hacer (García 1961: 251).

\footnotetext{
El obispo Santiago José de Hechavarría es el primer natural de tierras cubanas que llegó a ser designado como obispo de Cuba. Con anterioridad, Dionisio Rezino y Ormachea había sido el primer individuo nacido en esta isla consagrado como obispo, y llegó a desempeñarse, por un corto periodo de tiempo, al frente del obispado cubano (Suárez 2003).
} 
En otro momento, lamentándose de la separación de Bernardo de Gálvez y Cagigal, agregó: "Pero, ¿qué habría de suceder? Cagigal tenía a su lado por edecán y consejero íntimo al famoso Miranda, capaz de sembrar la discordia en el paraíso" (García 1961: 211).

Bernardo de Gálvez también acusó a Miranda de los 'tropiezos' que había tenido Cagigal al frente de la Capitanía cubana: "A que debo añadir a V. E. - expresó en una carta a su tío José- que prosiguiendo cada día peor este oficial en producir especies perjudiciales y esparcir la cizaña entre los jefes, se hace menos digno de encargo o confianza alguna" (García 1961: 229).

Dos años después de su salida de Cuba y del ejército español, en abril de 1785, Francisco de Miranda envió una Representación al monarca español en la que señaló, a su juicio, los responsables de la embarazosa situación que vivió en La Habana (Miranda 1978b: 421).

En primer orden señaló el procedimiento que había ejercido en su contra el ministro de Indias, los recelos de Bernardo de Gálvez y la denuncia solapada del obispo de Cuba, Santiago José de Hechavarría. A este último, señaló como el que había informado a la corona hispana de su supuesta responsabilidad en la visita del general inglés Campbell a la fortaleza de El Príncipe, asegurando que su implicación era completamente falsa y que todo había sido tramado por "este prelado intrigante y bullicioso" (Miranda 1978b: 428).

Sin embargo, Miranda no presentó pruebas de la implicación del alto prelado criollo, como tampoco lo permite concluir la información que se ha dispuesto para el presente escrito. Además, el venezolano desconocía que otras personalidades de este mismo contexto cubano caribeño, como Francisco de Saavedra y Bernardo de Gálvez, habían enviado a la corte ibérica desfavorables informaciones sobre su persona.

Sobre el seguimiento inquisitorial, debe tenerse presente que la causa seguida en su contra fue lenta en la tramitación de las Sumarias y órdenes de detención, e ineficiente cuando se le orientó al inquisidor de La Habana para que procediera a su inmediata captura. Además, desde la perspectiva mirandina la incidencia del proceso decae en importancia, 
pues al parecer éste nunca conoció que era observado y seguido por el Santo Oficio.

Las acusaciones que le hicieron durante su estancia en Cuba, unidas a las estériles apelaciones que realizó el capitán general Cagigal para desmentirlas, fueron los factores que Miranda identificó como las principales injusticias que se cometieron en su contra en esta etapa y que, en consecuencia, erosionaron significativamente su condición de súbdito español. Como un signo de mayor fuerza, Miranda señaló en la mencionada Representación el desprecio con que el ministro de Indias se refirió en varias ocasiones a su persona dado su origen criollo. Al respecto, afirmó que la “desventaja mayor de todas para el ascenso que es ser 'americano', según la opinión general de estos reinos y particular del señor Ministro actual de Indias" (García 1961: 430).

RELACIONES SOCIALES Y ASCENSO CULTURAL

Durante su estancia en tierras cubano-caribeñas, Francisco de Miranda encontró amplias posibilidades para continuar ampliando sus horizontes culturales y para relacionarse con notables personalidades del área.

Así, en Pensacola adquirió varios libros de autores ingleses, como Chesterfield, Robertson, Milton y Addison (Miranda 1978b: 114). Con posterioridad, durante los más de tres meses que residió en Jamaica reunió 93 obras, en varios tomos, con un total de 305 volúmenes, en su mayoría en inglés. Entre éstos se encontraban libros de historia, geografía, atlas, náutica, viajes, estrategia militar, literatura, filosofía y varios diccionarios. También adquirió una copia de una carta de Cristóbal Colón, fechada en Jamaica en 1503, en idioma inglés.

En vísperas de su salida de Cuba, el balance que realizó sobre sus pertenencias devela hasta dónde había llegado en su afán de lector y hombre de gustos refinados. Su biblioteca personal ascendía a más de 150 títulos, la mayoría en varios volúmenes. Entre los temas más representativos se encontraban los filosóficos, penales, económicos, históricos y militares, 
además de importantes escritos de la literatura universal y científica de la época (Miranda 1978b: 364).

Aunque no existen documentos personales que permitan valorar los niveles de conocimientos adquiridos por Miranda durante esta etapa, es posible aquilatar su preparación intelectual tomando en cuenta el amplio dominio teórico y espíritu crítico que demostró una vez que salió de Cuba y llegó a Estados Unidos, en 1783.

En los intercambios que sostuvo con notables personalidades norteamericanas, el venezolano no sólo opinó, sino que también juzgó y criticó con sólidos argumentos las bases sobre las que se erigía la nueva sociedad. Por ejemplo, sobre su encuentro con Samuel Adams, signatario de la Declaración de Independencia, Miranda escribió en su Diario:

Tuvimos charlas muy amplias acerca de la Constitución de esta república, y a dos objeciones que le presenté sobre la materia, manifestó su acuerdo conmigo, después que meditó bien los puntos. La primera fue: icómo en una democracia, cuya base era la virtud, no se señalaba puesto a ésta, y por el contrario, todas las dignidades, y el poder se daban a la propiedad que es justamente el veneno de una república semejante? La otra fue, la contradicción que observaba entre admitir como uno de los derechos de la humanidad, el tributar culto al Ser Supremo del modo y forma que le parezca, sin dar predominancia a ley o secta alguna, y que después se excluya de todo cargo legislativo o representativo al que no jurase ser de religión cristiana. Grandes solecismos, sin duda (Miranda 1978c: 305).

Adams, por su parte, valoró la personalidad mirandina como la de "un erudito clásico, de un hombre de saber universal, de un gran general, y maestro en todas las ciencias militares, poseedor de una gran sagacidad, una mente inquisitiva, y una curiosidad insaciable" (citado por Bohórquez 2003: 99). Otros norteamericanos le catalogaron como un: "inteligente extranjero y buen observador"; "hombre de virtudes y talentos"; y: "un ciudadano del mundo, que recorre con la intención de aumentar el cúmulo de sus conocimientos, que están lejos de ser insignificantes" (Miranda 1978c: 377-388). 
A tono con sus refinados gustos, en el mobiliario que reunió en La Habana sobresalen muebles de caoba y cedro, cuadros y láminas con marcos dorados, un canapé con vestiduras de indiana, cortinas, guarda-brisas, una hamaca americana, silla de montar y una volanta. Además, candeleros, cafeteras, cubiertos de plata, cobre y loza fina y superfina. Menaje que debió adornar los espacios de una confortable vivienda capitalina, a tono con las suntuosas residencias y amplias calles que se venían erigiendo en la capital cubana, en la segunda mitad del siglo XVIII.

Sus relaciones sociales abarcaron un nutrido círculo de personas de la aristocracia habanera y de la alta jerarquía militar hispana y caribeña. Entre éstos se encontraban los condes de Buena Vista, de Casa Montalvo y de Vallelano; los marqueses Justiz; el Barón de Kessel; y el jefe de la Escuadra de la Real Armada, Juan Tomaseo. También la señora Ana María Montero de Carvajal, Don Gabriel Peñalver y Cárdenas, el comisario de Guerra y Marina en La Habana, Francisco Javier Matienzo, y otros.

\section{LOS PASOS FINALES DE UN COMPLEJO PROCESO}

En los meses finales de 1782, cuando Cagigal y Miranda se preparaban para regresar a España, un anunciado acontecimiento añadió mayores agravantes a la ya tensa situación: Luís de Unzaga y Amézaga asumió el puesto de gobernador y capitán general de Cuba.

El nuevo gobernante, sin embargo, no prestó inmediata atención a las reales órdenes que disponían la reclusión de Miranda. Por su parte, el Tribunal de Cartagena, después de haber recibido la copia del expediente y la orden del Supremo Consejo para su arresto, ordenó a su comisario en La Habana que lo detuviera. Mas, por razones desconocidas hasta hoy, este funcionario no logró ubicarlo e informó al Tribunal y al comisario inquisitorial en Cádiz que el acusado ya había regresado a España con el regimiento de Aragón.

Pero Francisco de Miranda y Juan Manuel de Cagigal aún estaban en Cuba y conocían que a su regreso a la península debían defenderse de las 
graves acusaciones que se le imputaban. Para enfrentar este paso, Miranda comenzó a preparar una serie de documentos que le podrían hacer valer su destacado servicio a las armas hispanas. De Cagigal obtuvo un certificado sobre su incorporación al ejército español y otro por haber alcanzado el grado de teniente coronel, debido a su actuación en la conquista de Pensacola.

Al mismo tiempo, solicitó constancias escritas sobre lo ocurrido durante la visita de Campbell a La Habana. A su petición respondieron una veintena de altos oficiales españoles y miembros de la aristocracia habanera, como Gabriel Peñalver y Calvo, el conde de Vallelano, el conde de Buena Vista, el marqués del Real Socorro y el conde de Casa Montalvo. Todos coincidieron en resaltar su inocencia. En similar sentido, también solicitó:

en la mejor forma de derecho ante el nuevo gobernador y capitán general don Luís de Unzaga, solicitando haga declarar bajo juramento a don José Montesinos, cómo era cierto que había acompañado a Campbell al Castillo del Príncipe y ordene reconocer oficialmente las firmas y el contenido de los testimonios que presenta, los que niegan su participación en la aludida visita (Miranda 1978b: 379).

Unzaga aceptó la petición mirandina y legitimó todo el proceso al certificarlo ante un escribano público. Por su parte, Montesinos se declaró pleno responsable de todo lo ocurrido durante la visita de Campbell a la fortaleza habanera.

Pero el 14 de abril estos trámites se truncaron de repente, pues según contó Miranda a Cagigal en una carta fechada dos días después:

Hallábame, con el permiso de V. E., en el lugar de Regla tomando los aires, ínterin se metía lastre y recorría un poco la fragata que nos conducía a España (motivo porque arribamos) y anteayer se apareció en la casa donde asistía, un ayudante del señor Gobernador y Capitán General de esta Isla, inquiriendo por mi persona que justamente estaba fuera de casa; y se fue ofreciendo volver luego. Poco después, y antes de llegar yo a ella, supe confidencialmente que de positivo se había dado orden para arrestarme, privado de toda comunicación por escrito o de palabra, y que esto dimanaba de pliegos que la noche anterior habían llegado en un correo del Guárico o España (Miranda 1978b: 418). 
En esta propia misiva, le comunicó a Cagigal su decisión de: "marchar a Europa por las provincias anglo-americanas del Norte" (418).

Así, mientras Cagigal y sus tropas emprendieron la travesía atlántica de regreso a España, Miranda zarpó el 1o. de junio de 1783, a bordo de la balandra norteamericana Prudent, hacia los nacientes Estados Unidos de América.

En otra carta que envió a Cagigal el propio día 14, Miranda se elevó por encima de las dificultades que tensaban el momento para mostrar que su decisión de salir precipitadamente de Cuba no fue sólo la vía para escapar de sus potenciales captores, sino también la posibilidad real de encauzar motivaciones más profundas. En esos términos le comunicó a Cagigal lo siguiente:

[...] para que $\mathrm{V}$. proceda con todo aquel conocimiento que es indispensable en los asuntos, a fin de que salgan conformes con la idea del interesado, le diré que la mía, en dirigirme a los Estados Unidos de América, no sólo fue por sustraerme a la atropella que conmigo se intentó, sino para dar al mismo tiempo principio a mis viajes en países extranjeros, que sabe V. fue siempre mi intención concluida la guerra; con este propio designio he cultivado de antemano con esmero los principales idiomas de Europa que fueron la profesión en que desde mis tiernos años, me colocó la suerte y mi nacimiento. Todos estos principios (que aún no son otra cosa), toda esta simiente que con no pequeño afán y gastos se ha estado sembrando en mi entendimiento por espacio de treinta años que tengo de edad, quedaría desde luego sin fruto ni provecho, por falta de cultura a tiempo (Miranda 1978b: 418).

Estas y otras ideas contenidas en la misiva son ilustrativas del grado de identificación que Miranda había adquirido con las concepciones más avanzadas del pensamiento filosófico de la época (Martínez 2016: 112). En particular su propósito de conocer otras sociedades y sus más variados adelantos, reflejan su dominio de las modernas teorías que defendían a la experiencia como el medio que podía aportar los contenidos sobre los cuales los principios de la razón debían ser aplicados. Sobre esta base, el mundo se había convertido en el gran libro que debía estudiarse y los viajes, en el medio para conocerlo. 


\section{MIRANDA EN CUBA: ANÁLISIS Y PRECISIONES}

Los factores que incidieron en el desempeño de Francisco de Miranda durante su estancia en Cuba agudizaron un conjunto de contradicciones del ámbito profesional e intelectual, que tributaron a la maduración de su pensamiento político y al inicio de un proceso que lo distanció de España.

En el plano profesional, es preciso recordar que Miranda dedicó una esmerada atención a su carrera, sobresaliendo por su dominio de varios idiomas, ciencias militares, historia, filosofía y otras materias. Además, su servicio como oficial del ejército español, tanto en África, Europa y el Caribe, le proveyó de una meritoria hoja de servicios.

De manera paradójica, durante su estancia en Cuba sólo recibió un ascenso militar y no obtuvo ninguna condecoración, situación con la que se mostró altamente insatisfecho. A ello se agregan las fuertes reprimendas que recibió por las supuestas faltas cometidas y que se materializaron en cinco órdenes cursadas para su arresto. Aunque los motivos que presentó la corte ibérica para apresarlo no estuvieron respaldados con los argumentos necesarios, éstos no fueron retirados ante los convincentes alegatos enviados por el gobernador de Cuba hacia las más altas esferas de gobierno.

Esta situación fue erosionando la fidelidad de Francisco de Miranda al gobierno español, al considerar contradictorio que, a pesar de su apreciable servicio militar, los más altos representantes del gobierno ordenaran severas medidas en su contra. ${ }^{8}$

Otras contradicciones se expresaron en el plano intelectual. Al respecto, el conocimiento que Miranda alcanzó durante su estancia en Europa y África le llevó a cuestionar algunas reglamentaciones hispanas, sobre todo las establecidas por la Inquisición. Entre 1780 y 1783 su intercambio

${ }^{8}$ A pesar de haber escapado, a Miranda se le juzgó y sentenció a la pérdida de su grado militar, a una fuerte multa y a diez años de prisión en una cárcel española en Africa. Juan Manuel de Cagigal fue detenido al llegar a España y despojado de todos sus bienes, hasta que en 1799 fue llamado nuevamente a las filas del ejército. Transcurridos 19 años de estas acusaciones, ambos criollos fueron absueltos por un Tribunal del Consejo de Indias. 
con el mundo exterior se incrementó, sobre todo por sus lecturas y su visita a varios territorios caribeños, entre los que se incluyó una temporada en Jamaica, por entonces bajo dominio británico. Así, pudo comparar en la práctica las diferencias entre los avances que se extendían por el mundo moderno y los rígidos límites políticos, culturales y religiosos que imponía el dominio ibérico, tanto en la metrópoli como en sus colonias.

Estas contradicciones formaban parte de una contraposición mayor, que enfrentaba los intereses metropolitanos de España con los de sus dependencias coloniales en América. Aunque algunos historiadores han afirmado que Miranda, al salir de Cuba, estaba decidido a luchar contra el dominio español sobre Hispanoamérica, no se han mostrado suficientes razones para respaldarlo.

A declinar estas afirmaciones tributan las declaraciones de los propios funcionarios españoles, quienes no presentaron en este periodo de ruptura ninguna acusación originada en el enfrentamiento político de Miranda a España. Un hecho corroborado además por la inexistencia en su archivo personal, de documentos fechados en esta etapa que señalen su decisión de separarse de la corona en pos de la lucha independentista hispanoamericana.

No obstante, en su pensamiento pudo albergar ideas relacionadas con la terminación del control colonial hispano sobre América, de las que se cuidaría de expresar en público o recoger en algún documento que pudiera caer en manos de las autoridades hispanas y ser usado en su contra.

De cualquier modo, fue a partir de su salida de Cuba cuando se crearon las condiciones para que Francisco de Miranda comprendiera plenamente las insalvables contradicciones que existían entre España e Hispanoamérica. Al mismo tiempo, para que valorara las inmensas posibilidades que se ofrecían para su región natal, una vez que fuera desplazado el dominio hispano e instaurado un sistema de gobierno libre e independiente.

Para alcanzar este nivel de comprensión, tributó decisivamente el intenso recorrido que realizó por Estados Unidos de América, entre 1783 y 1784, donde conoció directamente las experiencias de la recién concluida contienda militar y los progresos de la vida republicana. De modo particu- 
lar, constató la aplicación práctica de varios principios como las libertades individuales, la igualdad de derechos para todos los ciudadanos libres, los mecanismos democráticos y la separación del ejercicio de los poderes del Estado.

De esta forma, la elevada preparación intelectual que Miranda había alcanzado, su irreversible distanciamiento del gobierno español y la constatación directa de los inicios del proceso de construcción republicana en los Estados Unidos, favorecieron decisivamente la maduración de su pensamiento político. Situación que permite comprender por qué, apenas unos meses después de su precipitada salida de Cuba y de su virtual alejamiento del gobierno español, formulara sus primeros proyectos independentistas para Hispanoamérica (Miranda 1950: 9).

\section{BIBLIOGRAFÍA}

AlBI DE la Cuesta, Julio. La defensa de las Indias (1764-1799). Madrid: Ediciones de Cultura Hispánica, 1987.

ArChivo NaCional DE CuBA. Asuntos políticos. Legajos 3, 106 y 304 y Correspondencia de los capitanes generales. Legajo 30-A.

BAKER, R. "El proceso independentista de los Estados de América". Historia comparada de las Américas. Procesos independentistas. Patricia Galeana (coord.). Ciudad de México, unAM/IPGH/Siglo XXI, 2010.

Bencomo, HéCtor. Miranda y el arte militar. Caracas: Italgráfica, 2000. BOHÓRQueZ Morán, CARMEN L. Francisco de Miranda. Precursor de las independencias de la América Latina. La Habana: Editorial de Ciencias Sociales, 2003.

CórdobA, Diego. Miranda, soldado del infortunio. Ciudad de México: Beatriz de Silva, 1954.

GarCía, LaúTiCo. Francisco de Miranda y el antiguo régimen español. Caracas: ANH, 1961.

Guerra Vilaboy, Sergio. "Miranda en Cuba. Un capítulo decisivo en la vida del precursor de la independencia hispanoamericana". El papel de 
Miranda y su generación en la emancipación latinoamericana: identidad, integración regional y gobernabilidad. Carmen Bohórquez Morán y Christian Ghymers (comps.). Caracas: Ministerio del Poder Popular para la Cultura, 2006.

Kamen, Henry. La Inquisición española. Barcelona-México: Grijalbo, 1967.

MarTínez Hoyos, Francisco. Francisco de Miranda, el eterno Revolucionario. Barcelona: Arpegio, 2016.

Miranda, Francisco. Colombeia. Tomo I La Habana: Trejos Hermanos Sucesores, 1978a.

. Colombeia. Tomo II. La Habana: Trejos Hermanos Sucesores, $1978 \mathrm{~b}$.

. Colombeia. Tomo III. La Habana: Trejos Hermanos Sucesores, 1978c.

Archivos. La Habana: Lex, 1950.

NuCETE-SARDI, JosÉ. Aventura y tragedia de don Francisco de Miranda.

Caracas: Editorial González-González, 1956.

PADRÓN, WILFREDO. Cuba en la vida y obra de Francisco de Miranda. La

Habana: Ciencias Sociales, 2010.

PaRRA-PÉREZ, CARACCIOLO. Miranda y la Revolución francesa. Caracas:

Ediciones Culturales del Banco del Caribe, 1988.

PÉReZ-CabreRA, José Manuel. Miranda en Cuba (1780-1783). La Habana:

Academia de la Historia de Cuba, 1950.

PlaCer, Gustavo. Ejército y milicias en la Cuba colonial (1763-1783). La

Habana: Editorial de Ciencias Sociales, 2015.

RodríGuez de Alonso, Josefina. "Bosquejo biográfico de Francisco de Miranda". Francisco de Miranda. Colombeia. Tomo I. Caracas: Trejos Hermanos Sucesores, 1978.

SALCEDO, J. L. "Discurso en ocasión del bicentenario de la participación de Miranda en Pensacola". Boletín de la Academia Nacional de la Historia (1981): 64-78.

SPENCER, RoBerTSOn. La vida de Miranda. Caracas: Publicaciones del Banco Industrial de Venezuela, 1967. 
Sú́REZ, RAMÓn. Historia de la Iglesia católica en Cuba. Tomo I. Miami: Ediciones Universal, 2003.

TORRes, Constantino y GuerRa VIlaboy, Sergio. Historia universal. San Salvador: Editorial Imagen Contemporánea/Equipo Maíz, 2018.

TORRES-Cuevas, EDuARDo. "Lo que le debe la independencia de Estados Unidos a Cuba. Una ayuda olvidada". En busca de la cubanidad. La Habana: Editorial de Ciencias Sociales, 2006.

Uslar, ARTURo. Los libros de Miranda. Caracas: Ediciones del Cuatricentenario, 1966. 